\title{
Efficient Power Utilization Control Scheme for Hybrid Distribution Generation Grid
}

\author{
Mohamed M. A. Mahfouz ${ }^{1,2}$, Mohammed Alsumiri ${ }^{1, ~ *, ~ R a e d ~ A l t h o m a l i ~}{ }^{1}$ \\ ${ }^{1}$ Electrical and Electronics Engineering Technology Department, Yanbu Industrial College, Yanbu, Saudi Arabia \\ ${ }^{2}$ Electrical Power and Machines Department, Faculty of Engineering, Helwan University, Cairo, Egypt
}

Email address:

alsumiri@rcyci.edu.sa (M. Alsumiri), mahfouzm@rcyci.edu.sa (M. M. A. Mahfouz), althomalir@rcyci.edu.sa (R. Althomali)

${ }^{*}$ Corresponding author

\section{To cite this article:}

Mohamed M. A. Mahfouz, Mohammed Alsumiri, Raed Althomali. Efficient Power Utilization Control Scheme for Hybrid Distribution Generation Grid. Journal of Electrical and Electronic Engineering. Vol. 9, No. 1, 2021, pp. 26-32. doi: 10.11648/j.jeee.20210901.14

Received: February 16, 2021; Accepted: March 1, 2021; Published: March 4, 2021

\begin{abstract}
Micro Grids (MGs) are well described as distribution systems with integrated distributed energy resources, i.e. photovoltaic (PV) and wind power generation systems. MGs can improve the quality of power by maintaining voltage levels and reducing the cost of energy supply. Despite the obvious advantages of distributed generation, technical operating and controlling challenges related to MGs are immense to maintain voltage and frequency stabilities during variable loading and emergency condition. This paper proposes an efficient an overhaul maximum power conditioning control system of micro grid feeds from PV modules and wind turbine. The PV power system utilizes two-stage energy conversion system topology, i.e. a DC/DC chopper circuit and voltage source inverter (VSI) that satisfies the MG technical requirements. For the proposed PV maximum power point tracking (MPPT), the boost chopper duty cycle is being adjusted to set the PV panel operating point to a maximum power point. Whereas for the proposed wind turbine, the pitch angle controller is developed to force the wind turbine to reaches its optimal operation at low and medium wind speeds. During high wind speeds, the pitch angle is changed to minimize the aerodynamic power. The dynamic model and control of the investigated MG for both transient and steady states operations are illustrated. Furthermore, the control strategies for maintaining the maximum energy conversion and to obtain voltage stability under multiple operating conditions are presented.
\end{abstract}

Keywords: Micro Grid, Pitch Control, Photovoltaic Array, Voltage Source Inverter, Wind Energy

\section{Introduction}

In today's evolving power systems research, Distributed Generation (DG) has had the rapid growing area of research. Despite the fact that the concept of power generation from different isolated locations is not novel, researchers have introduced the concept of integrating renewable energy sources as well as fossil fuel generators of a small capacity to the centralized power system grid [1].

The step toward more decentralized power system has been necessary because of many reasons. It has been concluded that these reasons are the increased environmental awareness and electricity market deregulation [2]. A new system called micro grid is formed when different DG units are interconnected to distribution network. Increasing reliability and decreasing losses can be obtained by reducing the power flowing from transmission and distribution networks. It can be achieved by having micro grids with DG close to load center. Micro grids can also enhance system performance by relieving the overloading of the network and aiding the operating engineer to speed up the restoration process after blackouts due to fault or emergency conditions [3]. However, for direct energy supply to the grid, DG used in micro grids might be technically not suitable. It is recommended to use inverter to interface DG with MG to maintain the desired voltage and frequency under time varying loads. Ensuring stable MG's operation under abnormal conditions as well as power quality needs development of complicated control strategies for the interfaced converters [4-6]. In recent researches, machine learning techniques have been employed for micro-grid systems. However, these algorithmic techniques need a proper training and certainty pre-definition to improve the system 
operation under abnormal operations [7, 8].

In the last few years, PV arrays have been growing fast as one of the nominated DG sources. This is principally because of the improvement in PV technology and conversion efficiency as well as reducing the PV system installation costs. It has been very well known that to allow maximum power extraction form the PV MPPT is implemented. The MPP operation of a PV module depends on ambient temperature and solar irradiance. The system operating point can be controlled and successful achievement of MPP can be ensured by controlling either the DC-DC or the DC-AC converters. Many algorithms would be successfully implemented to achieve MPPT operation, i.e. constant voltage, perturb and observe parasitic capacitance and incremental conductance [9]. Similarly, wind generation systems are preferred to extract maximum possible energy from wind, therefore MPPT is generally implemented so maximum output is ensured at nominal wind speeds. In case of high wind speeds, it is essential to dissipate some excess wind power to keep away from the risk of wind turbine damage. Therefore, a development of effective wind turbine power control is recommended. There are various strategies of power control on recent wind turbines technology; one of these is a pitch control. Following a pitch control based wind turbine, the power output is being checked quite a few times per second, if the output power exceeded the cut-off rang, the rotor blades immediately revolve the turbine's blades to some extent out of the wind. In opposition, the blades are revolving back to face the direction of the wind every time the wind speed drops again [10]. In order to design a pitch controller wind turbine, experience is required to obtain the optimal angle of the rotor blades which ensure getting the most output for various speeds. This paper studies transients and steady states behavior of a micro grid under varying climate conditions and three phase fault. With the intention of evaluate the system dynamics; a detailed system model is created. So that the micro grid components that include power conditioning system can be simulated. MPPT for PV system using constant voltage (CV) algorithm is illustrated. Also pitch control for wind turbine under wind speed fluctuations and different solar irradiance is introduced. This paper is structured as the following; the layout of the investigated MG is demonstrated in Section II. Section III gives solar and wind energy driven DG units modeling and presents the description of the proposed overhaul control technique to have the maximum power conditioning. In Section $\mathrm{IV}$, the investigated conditions along with results are discussed. Finally, Section V is the conclusions.

\section{Micro-Grid System Model}

The single line diagram of the investigated micro-grid is presented in Figure 1. The MG system configured using $22 \mathrm{kV}$ interconnected network with $200 \mathrm{~kW}$ PV panel and $660 \mathrm{~kW}$ variable speed wind turbine. Both of WT and PV are connected to the grid with each other with three short transmission lines with length of $20 \mathrm{Km}$. The studied PV array is poly crystalline silicon which is formed using 36 cells per module. The open circuit voltage is $20.8 \mathrm{~V}$. The system configured using 33 series modules and 119 parallel modules. The PV bus has a local load of $120 \mathrm{~kW}$ and reactive power of $50 \mathrm{kVar}$, while the wind local bus load is $280 \mathrm{~kW}$ and $100 \mathrm{kVar}$. Using DC/DC boost converter and three-phase two-level DC/AC inverter PV modules are connected to the grid. Then the PV modules are connected to the DG through a transformer $6 \mathrm{kV} / 22 \mathrm{kV} 250 \mathrm{kVA}$, while, the WT is connected to MG through $800 \mathrm{kVA}, 690 \mathrm{~V} / 22 \mathrm{kV}$ transformers. The turbine rated wind speed is $12 \mathrm{~m} / \mathrm{s}$ with pitch control and it is coupled to self-excited induction generator (SEIG). In the case of SEIG with fixed capacitor, extra source of reactive power from the grid is required. Providing this reactive power from the grid system could improve system dynamic performance. The DG voltage variations are recorded due to wind speed and radiation flections.

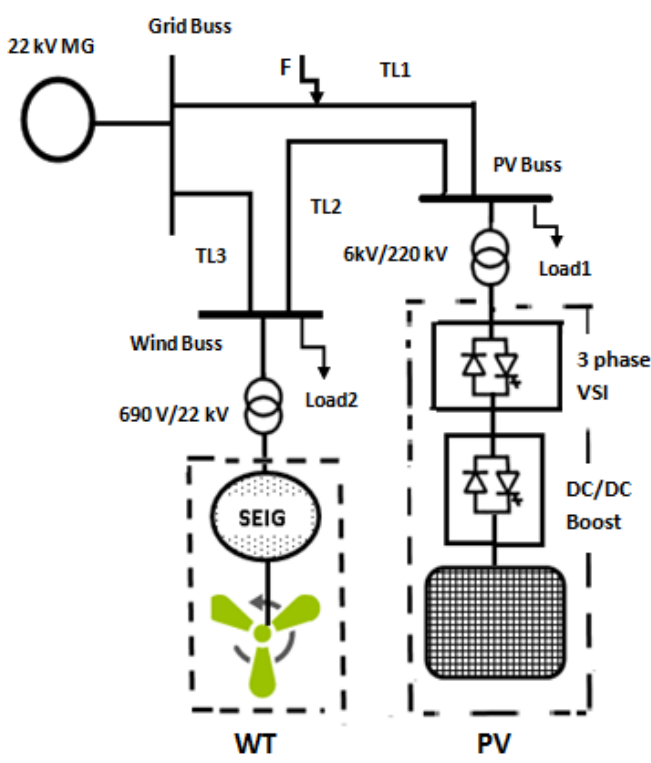

Figure 1. Investigated micro grid single line diagram.

\section{Proposed Maximum Power Overhaul Scheme}

The proposed overhaul control scheme target is to have maximum power conditions for both PV array and the wind turbine. For PV array, MPPT constant voltage is applied for the boost converter and the PWM based three phase two level inverter, while for wind turbine pitch control being used. In this section the detailed descriptions for both algorithms are introduced.

\subsection{PV Array MPPT}

To simulate a real behavior of the system an exact equivalent circuit modeling including the physical aspects of a p-n junction is necessary. A model of the PV cell could be developed using a parallel DC current source and diode. Doing so, the amount of electrons that escaped because of charge recombination mechanism and diffusion can be represented. A couple of resistors, Rs and $R_{p}$, represent the effective contact resistance of the PV cell and the PV cell internal resistance respectively. The values of $R s$ and $R_{p}$ are found either by measurements or can be obtained using curve fitting technique derived from the PV cell I-V characteristic. 
In addition, source current $\mathrm{I}_{\mathrm{ph}}$ represents the photo cell current. The relationship between the PV terminal voltage and output current of the cell is given as below, [11]:

$$
I=I_{p h}-I_{r S}\left[\exp \left(\frac{q\left(V+I R_{S}\right)}{A K T}\right)-1\right]-\frac{V+I R_{S}}{R_{p}}
$$

Where; $\mathrm{A}$ is the ideality factor of a diode, $\mathrm{T}$ is the Kelvin temperature of the $\mathrm{PV}$ cell, $\mathrm{q}$ is the charge of the electron $\left(1.60217646 \times 10^{-19} \mathrm{C}\right), \mathrm{I}_{\mathrm{rs}}$ is the reverse saturation currents of the diode, $\mathrm{k}$ is $\left(1.3806503 \times 10^{-23} \mathrm{~J} / \mathrm{K}\right)$ which is the Boltzmann constant. A PV module consists of multiple PV cells. These modules can be connected in parallel or in series configurations to structure a PV array. By assuming high resistance value of $R_{p}$, the array current can be found as below:

$$
\begin{gathered}
I=N_{p}\left[I_{p h}-I_{r s}\left(\exp \left(\frac{q\left(V+I R_{S}\right)}{A K T N_{S}}\right)-1\right)\right] \\
I_{r s=} I_{r r}\left(\frac{T}{T_{r}}\right)^{3} \exp \left[\frac{E_{G}}{A K}\left(\frac{1}{T_{r}}-\frac{1}{T}\right)\right]
\end{gathered}
$$

Where; $I_{r s}$ is the short circuit current and $\mathrm{k}$ represents temperature coefficient of the short circuit current. S represents the $\mathrm{mW} / \mathrm{cm}^{2}$ solar irradiance. A grid-connected based PV power generation system has to deliver a maximum possible solar power extracted, to the MG regardless climate conditions. Consequently, the employment of a proper MPPT is preferred. The power obtained from the PV modules has non-linear relationship with solar radiation and ambient temperature. Based on the nonlinearity behavior, the PV output power varied constantly hence the optimal PV operating point must vary to ensure maximum energy conversion. To achieve this target, a control algorithm to have MPPT operation for both the boost and PWM inverter is proposed and its block diagram is illustrated in Figure 2. The constant voltage $(\mathrm{CV})$ algorithm is applied due to its simplicity for MPPT control method. It is illustrated that, the PV array operating point achieved MPP by manipulating the $\mathrm{PV}$ voltage to the desired reference voltage $\left(\mathrm{V}_{\text {ref }}\right)$. The desired reference voltage has to be the manufacturer VMPP of the PV module. This scheme supposes that temperature variations as well as individual insulation are of no consequence. Hence, the uncertainty of the MPP reference voltage is introduced. So it can be noted that $\mathrm{CV}$ algorithm is developed on the bases of roughlysteady ratio between VMPP and $\mathrm{V}_{\text {ocas }}$ below:

$$
\mathrm{V}_{\mathrm{MPP}} \cong \mathrm{kV}_{\mathrm{oc}}
$$

By regulating the array output voltage to calculated value, the MPP operation is obtained. The voltage measurements of the VPV are required so that the duty ratio of the DC/DC converter is designed.

\subsection{Booster Control}

It is well known that a boost chopper circuit is a power electronics converter which increases the output DC voltage to a level greater than the input DC voltage. Constant or regulated voltage operations of a boost converter can be met by implementing pulse width modulation (PWM) technique. In addition, regulated output voltage from variable input voltage can be derived by varying the duty ratio (d) of the chopper. The boost chopper operation can be governed by the following [12];

$$
\frac{V_{0}}{V_{i}}=\frac{T_{S}}{t_{\text {off }}}=\frac{1}{1-d}
$$

Whenever VMPP is determining, the $\mathrm{DC} / \mathrm{DC}$ boost converter can be controlled to ensure that the array terminal voltage is at MPP. As illustrated in Figure 2, the deviation between MPP desired the PV output voltages characterize the PI controller error. Hence, PI controller is designed to regulate the output voltage of the PV array by switching the IGBTs on and off at high frequency based on duty ratio. However, high switching frequency capability of the DC-DC boost converter decouples the dynamic performance of the PV modules because of the differences between voltage or current from that of the DC link capacitor, which offers good performance under different atmospheric conditions. Boost converter is employed in order to step-up the voltage level to match the grid voltage level.

\subsection{VSI Three Phase PWM Inverter Control}

Along a variety of modulation techniques for MMI, PWM is nominated because of its advantage of utilizing the DC link voltage efficiently. In addition, it minimizes losses caused by commutation and reduces the value of the total harmonics distortion (THD). The employed inverter topology is a three-phase two-level DC/AC inverter. The inverter constructed using IGBTs to minimize the switching losses. Based on the gating signals, the output terminal voltage is either zero or equal to the capacitor voltage, and could be expressed as the following, [13]:

$$
V_{\text {inv }}=N * V_{\text {cap }}
$$

Where, $\mathrm{V}_{\text {inv }}$, is the terminal voltage, $\mathrm{V}_{\text {cap }}$ is the capacitor voltage and $\mathrm{N}$ is gating signal. The value of $\mathrm{N}$ is either zero or one. Considering two-level inverter, the output alternating voltage with positive and negative values $\left(+\mathrm{V}_{\mathrm{dc}}\right.$ and $\left.-\mathrm{V}_{\mathrm{dc}}\right)$ is obtained by controlling the upper and lower IGBT. Mainly at the PCC, the inverter is being connected to the network via the impedance of coupling transformer. The coupling transformer impedance is represented by the equivalent resistance and inductance. It is worth mentioning that the mutual equivalent inductance allows the consideration of the transformer's magnetizing inductance. The current controller objective is to eliminate the error between the inverter output and desired currents. Designing a current controller requires transforming the output three phase currents to a developed dq rotating reference frame. The description of the relationship between $\mathrm{V}_{\mathrm{dc}}$, which is the DC side voltage, and $\mathrm{V}_{\mathrm{inv}}$, which is the generated $\mathrm{AC}$ voltage, in the dq-frame is given by:

$$
\left[\begin{array}{c}
V_{i n v, d} \\
V_{i n v, q}
\end{array}\right]=S_{a v, d q} V_{d c}
$$

Where; $\left(S_{a v, d q}=0.866 m_{i}\right)$ and $\mathrm{mi}$ is the inverter modulation index. By using a phase locked loops the grid frequency in locked and $\mathrm{Vq}$ is set to zero [11]. Real and reactive 
power injections from the PV array can be controlled using Id and Iq, whenever the grid voltage is relatively constant. Field oriented control (FOC) is implemented to allow real power injection from the inverter by controlling Id using PI current controller. The PI current controller force $I_{d}$ to track the desired signal $I_{d}$ REF which is generated from the DC link capacitor. Moreover, $\mathrm{I}_{\mathrm{q}}$ is set to zero hence the reactive power injection is zero. The control block diagram is presented in Figure 2.

Having constant DC voltage across the capacitor indicates that the power flows in, from the PV array, equivalent to the power flows out to the inverter [14]. The capacitor input power is controlled to ensure MPP operation of the PV modules by controlling the DC-DC chopper circuit. The $\mathrm{I}_{\mathrm{d}-\mathrm{REF}}$ is obtained from the difference between Pin and Pout based on to the below equation:

$$
I=\frac{1}{V_{d}}\left(K_{p}\left(P_{\text {in }}-P_{\text {out }}\right)+K_{I} \int\left(P_{\text {in }}-P_{\text {out }}\right) d t\right)
$$

Where $K_{I}$ is the integral constant $K_{P}$ is the proportional constant of the controller. $V_{d}$ is the d-axis element of the voltage at PCC. The output of the PI current controller is the modulation index $\mathrm{m}$, which is injected to PWM switching circuit.

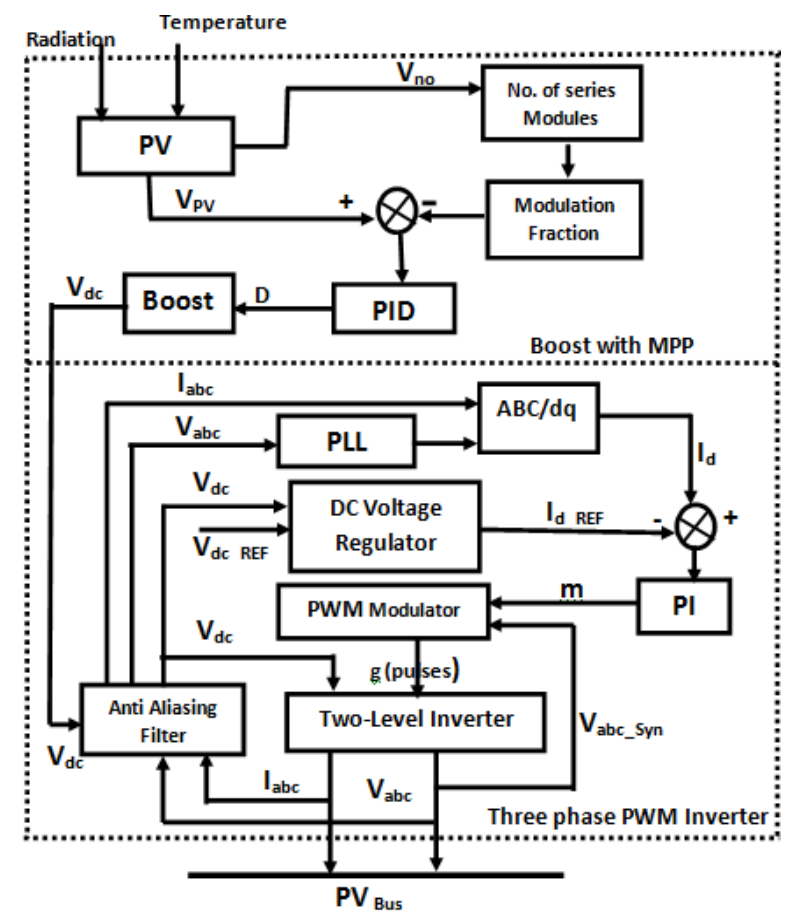

Figure 2. PV grid connected control block diagram.

\subsection{Wind Turbine Pitch Control}

The variable speed wind turbine extracted power affected by some key aspect such as the total power offered by the wind, the machine's power curve and the performance of the machine under wind speed variations, which is mainly depend on the used control algorithm [15]. The available power which can be extracted from the wind is as follows:

$$
p_{w}=0.5 \rho \cdot A \cdot C_{p}(\lambda, \beta) \cdot V_{w}{ }^{3}
$$

Where, $\mathrm{Pw}$ is the wind or aerodynamic power, $\rho$ is the air density, $A$ is the swept area of the turbine blades, $C_{p}(\lambda, \beta)$ is the power coefficient, $\lambda$ is the tip speed ratio and $\beta$ is pitch angle, $\mathrm{V}_{\mathrm{w}}$ is the wind speed.

The tip speed ratio (TSR) is defined as:

$$
\lambda=\varpi_{m} \frac{R}{V_{w}}
$$

Where, $\omega_{\mathrm{m}}$ is the mechanical speed of the rotor in $\mathrm{rad} / \mathrm{s}$ and $\mathrm{R}$ is the radius of the rotor. The characteristics of the wind turbine could be described using $\left(\mathrm{C}_{\mathrm{P}}-\lambda\right)$. It worth mentioning that for a constant speed operation, any variation in the wind speed will directly manipulate the TSR. Furthermore, the $C_{p}$ will change and the extracted power from the wind as well.

For variable speed operation, however, the operating rotor speed is regulated based on the instantaneous wind speed. Hence, the TSR can be kept at its optimal value and MPP operation is achieved. The power coefficient equation $C_{p}(\lambda, \beta)$ is employed in order to model the wind turbine behavior. Also, $\mathrm{C}_{\mathrm{p}}$ is used to evaluate the energy conversion efficiency. It is desired that the wind turbine always achieved maximum $C_{p}$ values in order to capture the maximum power from the wind [16-19].

$$
\begin{gathered}
C_{p}=0.5\left(\lambda-0.022 \beta^{2}-5.6\right) e^{-0.17 \lambda} \\
p_{T}=0.5 \rho . A . C_{p T}\left(\frac{R}{\lambda_{T}}\right)^{3} \varpi_{m}^{3} \\
p_{T}=K_{P}(R P M)^{3}
\end{gathered}
$$

Where; $\mathrm{P}_{\mathrm{T}}$ is the target power at max. $\mathrm{Cp}$;

$$
\mathrm{C}_{\mathrm{p}}(\mathrm{T})=\mathrm{C}_{\mathrm{p}}(\lambda, \mathrm{T})
$$

$\mathrm{K}_{\mathrm{P}}$ is the computed wind turbine data and RPM is the rotor speed. For a fixed-frequency application, such as the investigated application, the induction generator rotor speed has a slight variation above the synchronous speed according to the slip, while the wind speed may vary across a wide range. The pitch control technique is a most commonly employed approach for regulating the output power of a wind power generation systems. It reacts based on the deviations in the extracted wind power hence pitch angle of the blades is changed. It is generally used for speed control, power generation optimization and to start /stop the turbine. Wind energy generation system is recommended to always achieve a maximum $\mathrm{C}_{\mathrm{p}}$ operation.

During lower wind speed region, the wind power extracted by the wind energy generation system is below the maximum power rating of the wind, to achieve this objective; the pitch angle of the wind turbine is regulated to obtain the maximum possible $\mathrm{C}_{\text {pmax }}$. As the rpm changes according to wind speed, the pitch angle is changed to keep its optimum power. To fulfill this study, aim a proposed applied pitch control algorithm is shown in Figure 3 using PID pitch controller which generates the pitch angle required for capturing the maximum wind power. The PID uses the error between the desired maximum mechanical output power $\mathrm{P}_{\mathrm{m}-\mathrm{REF}}$ equal to (1pu) and actual captured mechanical power $\left(\mathrm{P}_{\mathrm{m}}\right)$, which resulting from the variable wind velocity to determine the 
required pitch angle. The desired pitch angle output is connected to a limiter to make sure that the pitch angle value is within the permissible range and by setting the limiter $\left(\mathrm{P}_{\max }\right)$. The PID gains for system controller are designed off line using the Zeigler-Nicholas rules for tuning their parameters.

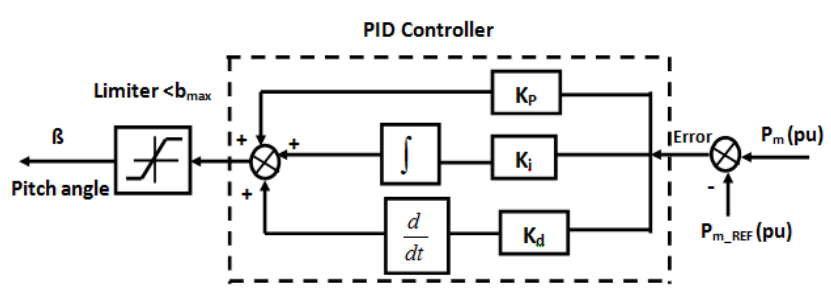

Figure 3. Pitch control block diagram.

\section{Simulation Results}

For the studied micro grid system illustrated in Figure 1, the micro-grid sources considered comprise of a photovoltaic generator equipped with constant voltage MPPT and a variable speed wind turbine equipped with maximum power pitch controller. The system has been tested under different normal and abnormal operation conditions. As a sample of input weather data, the variations in solar irradiance and wind speeds are illustrated in Figure 4. Three phase faults have been created to the midpoints of the feeders that are connecting the grid with the two PCC of the wind farm and PV array. Due to the short lines of both the feeders, the behavior of the system is almost the same in both faulty cases. The simulation results are shown to overview the system's parameters response for the case of three-phase fault on the feeder connecting the grid with the PCC of the wind bus. This fault is initiated at ( 2 sec's) for a duration of $(1 \mathrm{sec})$. Figure 5 represents the dynamic performance of the grid bus in terms of current and voltage as well as active and reactive power also the simulation results demonstrate the condition of active power feeding the grid. During abnormal operation, i.e. fault, the supplied current and power are subject to rapid increase. After fault clearance the current and power are maintained to their nominal values.

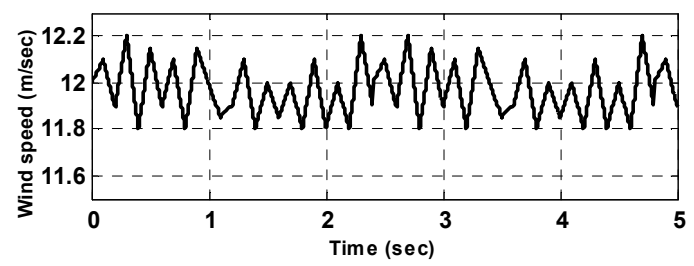

(a)

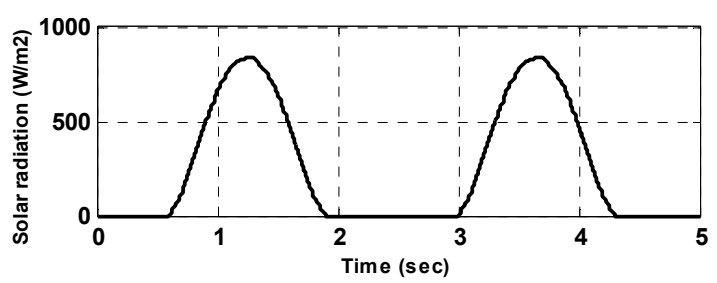

(b)

Figure 4. Climate conditions (a) wind speed (b) solar irradiance.
The wind speed is varying as shown in Figure (4.a), while the corresponding bus parameters; voltage, current and both active and reactive power are injected at wind-PCC. Pitch angle, electric torque and the rotor speed are shown in figure (6). Under faulty condition, the magnitude of the voltage at wind-PCC is dropped suddenly hence the extracted wind power as a result is decreased as illustrated in Figures (6.a) and (6.b) respectively. While in Figure (6.c), the pitch controller regulates the pitch angle to follow the $C_{\text {pmax }}$ operating mode according to the fact that the power is controlled to a level equal to the rotor speed cubed. The pitch angle control succeeded to keep the rotor speed constant to avoid any acceleration for the generator rotor as introduce in Figure 6.d where the corresponding electric torque is shown in Figure (6.e). The operating point will be reset again to $C_{p \max }$ operating mode after fault clearing. This is achieved according to the pitch mechanism capability and efficiency in fast controlling of the maximum extracted wind power. Moreover, by keeping the rotor speed constant the rotor stability is enhanced.

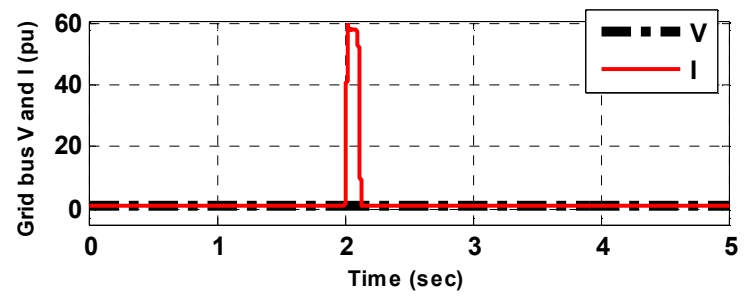

(a)

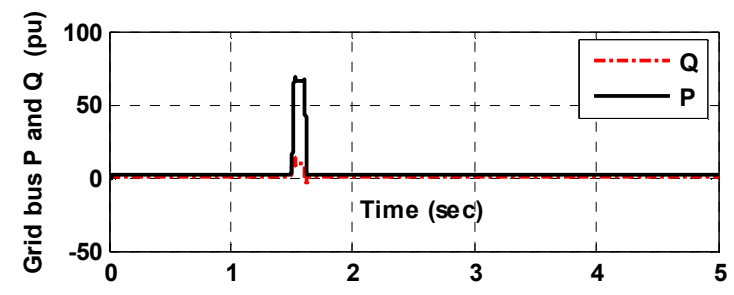

(b)

Figure 5. Grid bus variables (a) Voltage and current (b) active and reactive power.

The solar radiation is forced to vary according to day and night timings as described in Figure (4.b).

The corresponding power generated by PV system can be illustrated in Figure (7.a). It can be figured that the output power of the PV is perfectly matches the maximum power expected based on the solar irradiance. The MPP operation has been achieved successfully by employing the proposed constant voltage algorithm.

Similarly, Figure (7.b) demonstrates PV-PCC's current and voltage variations at the distribution feeder. The PV-PCC voltage has been regulated to a fixed value which indicates a perfect constant voltage operation; however, during the fault the voltage reduced to $0.8 \mathrm{pu}$. At wind-PCC, the current shows a perfect matching of the desired value. It has been noted that there is a slight transient affect in the switched over power of the grid connected based PV system. This effect is caused by the decoupling loops of the d-q current controllers. 
In order to achieve constant voltage operation, the proposed MPPT control algorithm for the PV array is implemented to control the power electronics circuits. The Inverter performance variables are shown in Figure 8, i.e. the Boost duty (D), DC link voltage, three phase inverter, PWM modulation index and Inverter phase voltage during the three phase fault at midpoint of the wind-grid feeder. For the second case study, the system performance has been investigated with a fault at $5 \mathrm{~km}$ from PV-PCC. Actually, this case represents a short feeder in micro-grids.

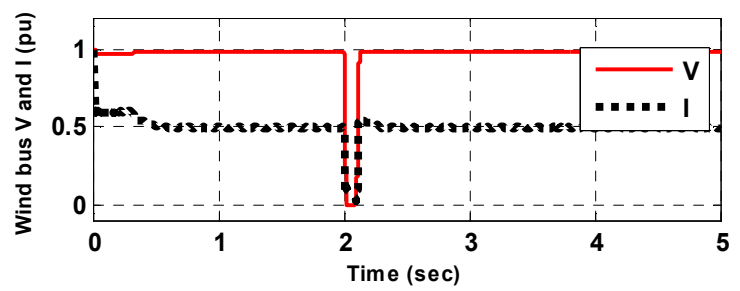

(a)

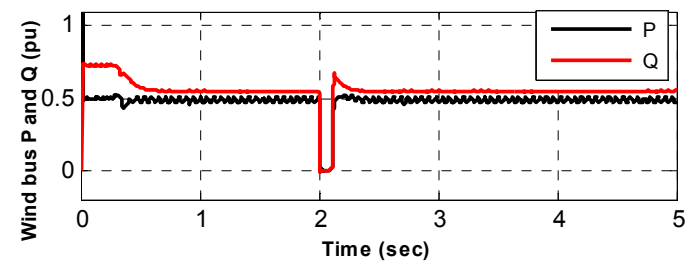

(b)

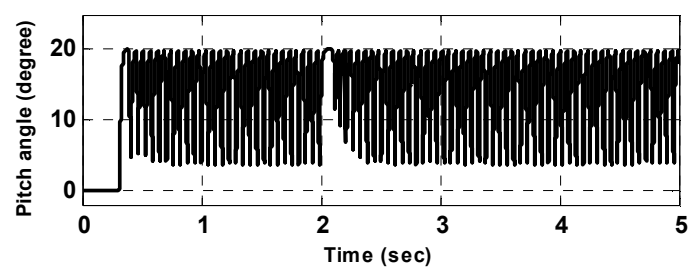

(c)

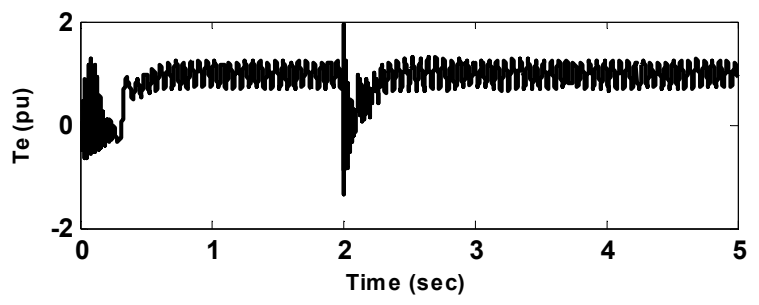

(d)

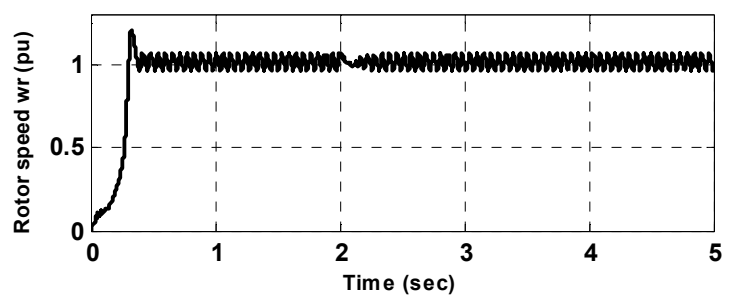

(e)

Figure 6. Wind-PCC (a) current and voltage (b) reactive and active power, (c) pitch angle, (d) electric torque and (e) mechanical speed.

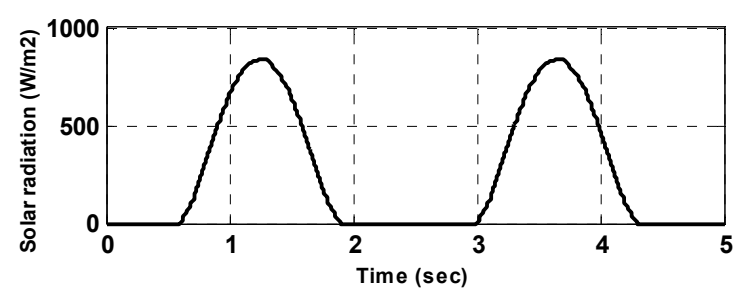

(a)

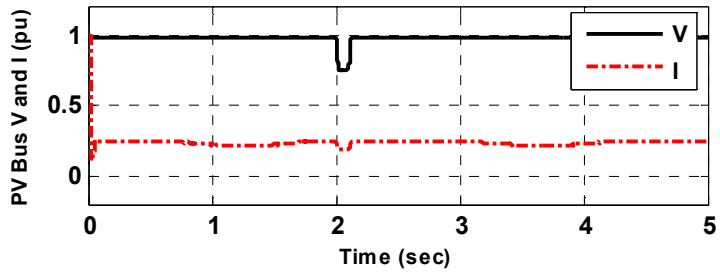

(b)

Figure 7. PV bus (a) PV system real power (b) voltage and current.

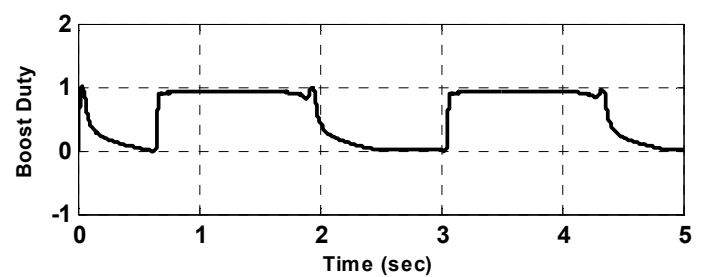

(a)

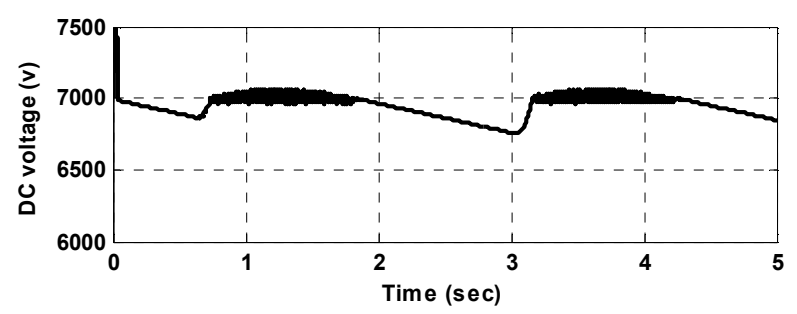

(b)

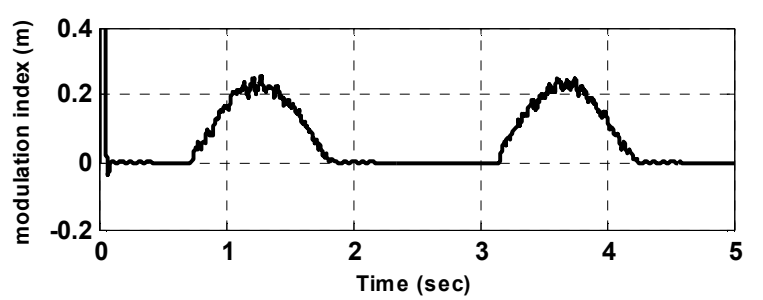

(c)

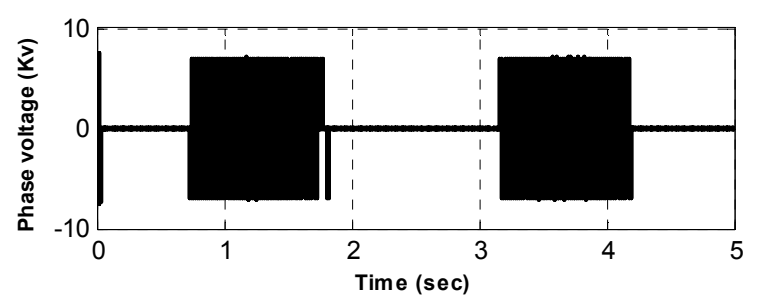

(d)

Figure 8. Chopper and Inverter variables (a) Boost chopper duty cycle, (b) Dc voltage Volt. (c) Modulation index and (d) Phase voltage. 


\section{Conclusion}

The paper presents a maximum power condition scheme for PV array and wind energy as renewable energy resources integration to micro-grid. Pitch control using PID was applied for wind turbine to regulate the wind generated electrical power around its maximum power at any wind speed. Thereby, the upper limit of captured power is the wind turbine rating. Two stage power conditioning system have been integrated, i.e. three-phase inverter and DC-DC boost converter. The integration of this power conditioning system enhanced the system's interface during different operating point operations or faulty conditions. Based on controlling duty ratio of the boost controller, a PI MPPT constant voltage controller has been developed. The detailed system model is derived, presented, and evaluated. The evaluation of the proposed control approach has been provided using the simulation results. The control approach has been evaluated during abnormal conditions, i.e. short circuit fault, wind speed variation and solar irradiance variation. The PI as well as PID controllers have been tuned in order to achieve a better dynamic performance of the system. The system shows a fast recovery of the reactive power as well as improved capability of severe disturbance rejection. In conclusion, the evaluation of the proposed control approach shows the successful achievement of optimal values in terms of voltage and power under variable wind speed and different solar irradiance.

\section{References}

[1] G. Pepermans, J. Driesen, D. Haeseldonekx, R. Belmans, and W. D'Haeseleer," Distributed Generation: Definition, Benefits and Issues", Energy Policy 33, PP. 787-798, 2005.

[2] WangShouxiang, Wang Hui, CaiShengxia, "A Review of Optimization Allocation of Distributed Generations Embedded in Power Grid", Automation of Electric Power Systems, 2009 (18).

[3] Wang Chengshan, Wang Shouxiang, "Study on Some Key Problems Related to Distributed Generation Systems", Automation of Electric Power Systems, 2008 (20).

[4] J. A. P. Lopes, C. L. Moreira, A. G. Madureira, "Defining Control Strategies for Micro Grids Islanded Operation," IEEE Transactions on Power System, Vol. 21, No. 2, PP. 916-924, 2006.

[5] A. Yazdani, P. P. Dash, "A Control Methodology and Characterization of Dynamics for a Photovoltaic (PV) System Interfaced With a Distribution Network," Power Delivery, IEEE Transactions on, Vol. 24, No. 3, PP. 1538-1551, July 2009.

[6] Salam, A. A., Mohamed, A., Hannan, M. A., \&Shareef, H. (2010). An improved inverter control scheme for managing the distributed generation units in a microgrid. International Review of Electrical Engineering, 5 (3), 891-899.

[7] Zhou, S., Hu, Z., Gu, W., Jiang, M. and Zhang, X. P., 2019. Artificial intelligence based smart energy community management: A reinforcement learning approach. CSEE Journal of Power and Energy Systems, 5 (1), pp. 1-10.

[8] Bui, V. H., Hussain, A. and Kim, H. M., 2019. Q-learning-based operation strategy for community battery energy storage system (CBESS) in microgrid system. Energies, $12(9)$, p. 1789.

[9] Wei LI, Luc, Jean -Andre GregoireBélanger, "Control and Performance of a Modular Multilevel Converter System", CIGRÉ Canada, Conference on Power Systems Halifax, September 6- 8, 2011.

[10] Jamal A. Baroudi, VenkataDinavahi, and Andrew M. Knight "A Review of Power Converter Topologies for Wind Generators", El Sevier Renewable Energy Journal Vol. 32, PP 2369-2385, 2007.

[11] Ahmed S. Khalifa, Ihab F. El-Saadany, "Control of three phase grid connected Photovoltaic array with open loop maximum power point tracking" IEEE PES General Meeting, July 26-29, 2011 Detroit, MI, USA.

[12] J. Selvaraj, N. A. Rahim, "Multilevel Inverter For Grid-Connected PV System Employing Digital PI Controller," Industrial Electronics, IEEE Transactions on, vol. 56, no. 1, pp. 149-158, Jan. 2009.

[13] W. Libo, Z. Zhengming, and L. Jianzheng, "A Single-Stagethree-Phase Grid-Connected Photovoltaic System With Modified MPPT Method And Reactive Power Compensation", IEEE Transactions on Energy Conversion, vol. 22, no. 4, pp. 881-886, 2007.

[14] H. Patel, V. Agarwal, "MPPT Scheme For A PV-Fed Single-Phase Single-Stage Grid-Connected Inverter Operating In CCM With Only One Current Sensor", Energy Conversion, IEEE Transactions on, Vol. 24, no. 1, PP. 256-263, March 2009.

[15] Y. Guo, S. H. Hosseini, J. N. Jiang, C. Y. Tang, R. G. Ramakumar, Voltage/Pitch Control For Maximisation And Regulation Of Active/Reactive Powers In Wind Turbines With Uncertainties, IET, Renewable Power Generation, Vol. 6, Issue 2, PP. $99-109,2012$.

[16] Alsumiri, M., Li, L., Jiang, L., \& Tang, W. (2018). Residue Theorem based soft sliding mode control for wind power generation systems. Protection and Control of Modern Power Systems, 3 (1), 24.

[17] Abdel-Raheem Youssef, Mahmoud A. Sayed, M. N. Abdel-Wahab, Gaber Shabib Salman, MPPT Control Technique for Direct-Drive Five-Phase PMSG Wind Turbines with Wind Speed Estimation, International Journal of Sustainable and Green Energy. Vol. 4, No. 5, 2015, pp. 195-205. doi: $10.11648 /$ j.ijrse.20150405.14.

[18] M. Magesh Kumar, R. Sundareswaran. PMSG Based Wind Energy Conversion with Space Vector Modulation. International Journal of Energy and Power Engineering. Vol. 4, No. 3, 2015, pp. 146-152. doi: 10.11648/j.ijepe.20150403.13.

[19] Mahmoud M. Hussein, Tomonobu Senjyu, Mohamed Orabi, Mohamed A. A. Wahab, Mohamed M. Hamada. Simple Sensorless Maximum Power Extraction Control for a Variable Speed Wind Energy Conversion System. International Journal of Renewable and Sustainable Energy. Vol. 1, No. 1, 2012, pp. 1-10. doi: 10.11648/j.ijrse.20120101.11. 